\title{
Discrepancies Between FDA-Required Labeling and Evidence that Payers Cite in Drug Coverage Policies
}

\author{
James D. Chambers, MPharm, MSc, PhD; Elle F. Pope, BA, MPH; \\ Colby L. Wilkinson, BA; and Peter J. Neumann, ScD
}

\begin{abstract}
BACKGROUND: FDA-required labeling summarizes certain data that the FDA relies on in its drug approval process. However, when determining coverage of specialty drugs, health care payers may consider dissimilar evidence.

OBJECTIVE: To compare evidence cited by the largest U.S. commercial payers in their specialty drug coverage policies with evidence featured in the labeling of the indicated drugs.

METHODS: We used the Tufts Medical Center Specialty Drug Evidence and Coverage Database (SPEC) - a database of specialty drug coverage policies issued by 17 of the 20 largest U.S. commercial health care payers-to identify coverage policies for drugs indicated for multiple sclerosis, rheumatoid arthritis, juvenile idiopathic arthritis, ankylosing spondylitis, and non-small cell lung cancer (NSCLC). These disease categories were selected because each was represented by multiple drugs. For each drug, we identified endpoints included in the clinical studies presented in the FDA-required labeling. Using SPEC, we identified randomized controlled trials (RCTs) and other clinical studies that at least 1 payer cited in its coverage policies for the included drugs. We reviewed the full text of each study to identify the endpoints reported. We categorized endpoints as identical to endpoints in the FDA-required labeling of the drugs; similar (e.g., a different measurement scale was used to evaluate the same endpoint); and different (the endpoint was not featured in the FDA-required labeling).
\end{abstract}

RESULTS: We included 41 drugs and reviewed 348 studies (246 RCTs and 102 other clinical studies). Of 2,237 endpoints, $63 \%$ were categorized as identical, $26 \%$ as similar, and $12 \%$ as different. Rheumatoid arthritis was the indication with the largest proportion of endpoints categorized as identical $(74 \%$ of endpoints in the RCTs cited by payers; $59 \%$ of endpoints in the other clinical studies cited by payers). NSCLC was the indication with the largest proportion of endpoints categorized as different (33\% of endpoints in the RCTs cited by payers; $37 \%$ of endpoints in the other clinical studies cited by payers).

CONCLUSIONS: Payers often report reviewing clinical evidence that goes beyond information included in FDA-required labeling. Our findings suggest that the FDA should continue engaging with the manufacturer and payer communities to appropriately facilitate communication of information necessary to allow for informed coverage decisions.

J Manag Care Spec Pharm. 2018;24(12):1240-46

Copyright $\odot 2018$, Academy of Managed Care Pharmacy. All rights reserved.

\section{What is already known about this subject}

When determining whether a manufacturer's promotional claims are appropriate, the FDA generally assesses whether the claims are consistent with the product's FDA-required labeling.

There are no legal limitations constraining the type of information that health care payers may consider when formulating coverage decisions for specialty drugs.

There is ongoing debate as to whether existing regulations appropriately facilitate the communication of information between drug manufacturers and health care payers that is necessary for informed coverage decisions.

\section{What this study adds}

Most clinical information that payers reported reviewing was identical or similar to information included in FDA-required labeling.

Payers reported reviewing clinical studies that included endpoints that differed from those reported in the drug's corresponding FDA-required labeling.

Study findings suggest that payers value information about drugs that goes beyond information included in FDA-required labeling.

T he Federal Food, Drug, and Cosmetic Act (FDCA) requires manufacturers to demonstrate a drug's safety and efficacy before they can market the drug. ${ }^{1}$ The FDCA also provides that a drug is "misbranded" if its "labeling" is false or misleading. ${ }^{2}$ The U.S. Food and Drug Administration (FDA) has interpreted this misbranding authority to prohibit promotional labeling of a drug for unapproved uses and has adopted an expansive view of what constitutes promotional labeling. ${ }^{3}$

There are no legal limitations constraining the type of information that payers may consider when making coverage determinations. Indeed, research has shown that payers report reviewing a wide range of evidence when determining their drug coverage policies, including randomized controlled trials (RCTs), observational studies, systematic reviews and metaanalyses, health technology assessments, cost-effectiveness analyses, and clinical guidelines. ${ }^{4,5}$ However, the FDA has maintained that certain data about company products that are not derived from pivotal clinical trials does not constitute 
"substantial evidence," and therefore may misbrand a product. As a result, manufacturers may feel limited in their ability to provide payers with the type of evidence that payers consider useful in making decisions. Because manufacturers must at times make a judgment on whether promotional labeling misbrands a product, payers may not always have ready access to the types of evidence that they consider useful to inform coverage determinations.

It is understandable that in making coverage determinations, payers would review evidence other than the information presented in FDA-required labeling. Information included in FDA-required labeling provides summaries that are intended to give prescribers important information needed to prescribe the product. While relevant, this information is insufficient to meet the needs of payers in making coverage determinations. For example, payers may want information regarding the budget impact of covering the drug, the drug's value, or how the drug performs relative to therapeutic alternatives in real-world settings. ${ }^{6}$ While such information is not necessarily included in FDA-required labeling, it is included in the Academy of Managed Care Pharmacy dossier, which is created by the product's manufacturer. ${ }^{7}$ Further, the reviews and advisory committee materials of the FDA Center for Drug Evaluation and Research also complement the labeling and dossier.

The purpose of this study was to compare the evidence that payers report reviewing for their drug coverage policies with clinical data featured in FDA-required labeling.

\section{Methods}

\section{Database of Commercial Payer Coverage Policies for Specialty Drugs}

This study used the Specialty Drug Evidence and Coverage Database (SPEC), developed by the authors, which details specialty drug coverage policies issued by 17 of the largest U.S. commercial payers (Appendix A, available in online article). The database includes 158 specialty drugs, accounting for 302 drug-indication pairs (77 of the drugs have multiple indications approved by the FDA), corresponding to 3,417 coverage determinations. The database consists of publicly available information extracted from the payers' coverage policies, prior authorization criteria, and utilization management guidelines relevant to specialty drugs. SPEC also includes details regarding evidence cited by the payers in their coverage policies. Coverage policies included in the database and analyzed for this study were current as of April 30, 2016.

\section{Included Indications}

We included drugs indicated for 5 diseases (multiple sclerosis, rheumatoid arthritis, juvenile idiopathic arthritis, ankylosing spondylitis, and non-small cell lung cancer). These diseases were selected because each was represented by multiple drugs in the database (Appendix B, available in online article).

\section{Clinical Endpoints Featured in FDA-Required Labeling}

We obtained the FDA-required labeling from the FDA's website for each drug in the database indicated for 1 of the 5 included diseases. ${ }^{8}$ We identified the endpoints included in the presented clinical studies from the "Clinical Studies" section of each drug's FDA-required labeling.

\section{Clinical Endpoints Featured in Clinical Studies that Payers Reported Reviewing}

Using SPEC, we identified RCTs and other clinical studies (e.g., prospective cohort studies and consecutive case series studies) that at least 1 payer in our sample reported reviewing in its coverage policies for the included drugs. We obtained and reviewed the full text of each study to identify the endpoints reported.

\section{Endpoint Categorization}

We categorized each endpoint included in the studies that payers reported reviewing into the following categories: (a) identical to an endpoint included in the FDA-required labeling, (b) similar to an endpoint included in the FDA-required labeling, or (c) different than the endpoints included in the FDArequired labeling.

Identical. We categorized an endpoint as identical if the same, or substantively the same, language was used to describe it (e.g., if a study included progression-free survival as an endpoint, we categorized it as identical if progression-free survival was also included as an endpoint in the FDA-required labeling).

Similar. An endpoint was categorized as similar if it met 1 of 3 criteria. First, we judged an endpoint as similar if it measured the same outcome as an endpoint in the FDA-required labeling but did so using a different measurement scale. For example, if the labeling included the American College of Rheumatology 20 response criteria- a multidimensional outcome measureand a study that a payer reported reviewing included the Disease Activity Score (DAS) - a different multidimensional outcome measure-we categorized the DAS as similar.

Second, we categorized an endpoint as similar if it constituted an individual component of a composite measure featured in the FDA-required labeling. For example, if the labeling included the Assessment in Spondyloarthritis International Society (ASAS) classification criteria-a composite measure that includes a visual analog scale (VAS) to measure pain-and a clinical study that a payer reported reviewing included a VAS to measure pain, we categorized the VAS as similar.

Third, we categorized an endpoint as similar if it measured the same clinical outcome as an endpoint in the FDA-required labeling but used a different metric. For example, if a clinical study included frequency of exacerbations as an endpoint, and a clinical study that a payer reported reviewing included the average number of exacerbations as an endpoint, we categorized the average number of exacerbations as similar. 
TABLE 1 Endpoints Featured in Studies Payers Reported Reviewing in Drug Coverage Policies

\begin{tabular}{|c|c|c|c|c|c|}
\hline & $\begin{array}{c}\text { Rheumatoid } \\
\text { Arthritis }\end{array}$ & $\begin{array}{l}\text { Juvenile } \\
\text { Idiopathic } \\
\text { Arthritis }\end{array}$ & $\begin{array}{l}\text { Ankylosing } \\
\text { Spondylitis }\end{array}$ & $\begin{array}{l}\text { Multiple } \\
\text { Sclerosis }\end{array}$ & $\begin{array}{l}\text { Non-Small Cell } \\
\text { Lung Cancer }\end{array}$ \\
\hline Number of indicated drugs & 10 & 5 & 6 & 13 & 7 \\
\hline \multicolumn{6}{|l|}{ Randomized controlled trials } \\
\hline RCTs that payers reported reviewing, ${ }^{a} \mathrm{n}$ & 92 & 7 & 18 & 99 & 30 \\
\hline Average RCTs per drug & 9.20 & 1.40 & 3.00 & 7.62 & 4.29 \\
\hline \multicolumn{6}{|l|}{ Endpoints } \\
\hline Number of endpoints across studies ${ }^{b}$ & 750 & 79 & 209 & 572 & 150 \\
\hline Identical, proportion of total, $\%$ & 74 & 56 & 47 & 59 & 59 \\
\hline Similar, proportion of total, $\%$ & 22 & 38 & 38 & 27 & 8 \\
\hline Different, proportion of total, $\%$ & 5 & 6 & 15 & 14 & 33 \\
\hline \multicolumn{6}{|l|}{ Other clinical studies } \\
\hline Other clinical studies that payers reported reviewing, ${ }^{a} \mathrm{n}$ & 32 & 12 & 7 & 35 & 16 \\
\hline Average clinical studies other than RCTs per drug & 3.20 & 2.40 & 1.17 & 2.69 & 2.29 \\
\hline \multicolumn{6}{|l|}{ Endpoints } \\
\hline Number of endpoints across studies ${ }^{b}$ & 158 & 82 & 53 & 142 & 42 \\
\hline Identical, proportion of total, \% & 59 & 64 & 60 & 60 & 50 \\
\hline Similar, proportion of total, $\%$ & 37 & 34 & 31 & 21 & 13 \\
\hline Different, proportion of total, $\%$ & 4 & 3 & 9 & 19 & 37 \\
\hline $\begin{array}{l}\text { a Sum of studies across all drugs. } \\
\text { bSum of endpoints across drugs and studies. } \\
\text { RCTs = randomized controlled trials. }\end{array}$ & & & & & \\
\hline
\end{tabular}

Different. We categorized an endpoint as different if it pertained to a clinical outcome or symptom that was not featured in the FDA-required labeling. For example, if a study evaluated the effect of a drug on fatigue, but an endpoint pertaining to fatigue did not feature in the FDA-required labeling, we categorized the endpoint as different. We further categorized clinical study endpoints that we determined to be different into 4 categories: clinical endpoints, patient-reported outcomes (PROs), clinician global assessments, and economic/health care utilization endpoints.

\section{Results}

We included 41 drugs across the 5 conditions and reviewed 348 studies (246 RCTs; 102 other clinical studies) cited in coverage policies by at least 1 payer in our sample. The included payers did not report reviewing evidence in their coverage policies for 2 drugs in our sample. We found an average of 8.5 studies cited by at least 1 payer per drug (6.0 RCTs per drug; 2.5 other clinical studies per drug), although this varied considerably by disease (Table 1). Other than for the 2 drugs for which no evidence was cited by payers in their reviews, payers reported reviewing at least 1 RCT for the included drugs. For an additional 9 drugs, payers reported reviewing at least 1 RCT but no other clinical studies.

The 246 RCTs included 1,758 endpoints of which we categorized $64 \%$ as identical, $25 \%$ as similar, and $11 \%$ as different. The 102 other clinical studies included 477 endpoints of which we categorized $59 \%$ as identical, $29 \%$ as similar, and $12 \%$ as different.

Rheumatoid arthritis was the indication for which we categorized the largest proportion of endpoints as identical (74\% of endpoints in RCTs; 59\% of endpoints in other clinical studies). Non-small cell lung cancer was the indication for which we categorized the largest proportion of endpoints as different (33\% of endpoints in RCTs; $37 \%$ of endpoints in other clinical studies).

Of the 269 endpoints categorized as different, 59\% were clinical endpoints; $22 \%$ were PROs; $10 \%$ were economic/health care utilization endpoints; and 3\% were clinical global assessments (Table 2). Of the 87 endpoints categorized as PROs, $28 \%$ were disease-specific quality of life measures; $26 \%$ were from the 36-Item Short Form Health Survey or related measures; 10\% were health utility measures (e.g., the EuroQol EQ-5D); and $10 \%$ were patients' global impressions of their health (Table 3). With the exception of treatment satisfaction, the remaining PROs assessed a single aspect of health (e.g., sleep, fatigue, depression, and cognitive functioning).

\section{Discussion}

We found that, across the studies that payers reported reviewing in their coverage decisions, $89 \%$ of information was identical or similar to information included in the FDA-required labeling. Of the endpoints included in the reviewed RCTs and other clinical studies, $89 \%$ and $88 \%$, respectively, were either identical or similar to information also in the FDA-required labeling. 
TABLE 2 Endpoints Featured in Studies Payers Reported Reviewing that Were Not Included in Drug's FDA Label

\begin{tabular}{|c|c|c|c|c|c|}
\hline & $\begin{array}{c}\text { Rheumatoid } \\
\text { Arthritis }\end{array}$ & $\begin{array}{c}\text { Juvenile Idiopathic } \\
\text { Arthritis }\end{array}$ & $\begin{array}{l}\text { Ankylosing } \\
\text { Spondylitis }\end{array}$ & $\begin{array}{l}\text { Multiple } \\
\text { Sclerosis }\end{array}$ & $\begin{array}{l}\text { Non-Small Cell } \\
\text { Lung Cancer }\end{array}$ \\
\hline \multicolumn{6}{|c|}{ Randomized controlled trials, $n$} \\
\hline Clinical endpoint & 4 & 3 & 16 & 37 & 52 \\
\hline Patient-reported outcome & 23 & 1 & 11 & 17 & 7 \\
\hline Clinician global assessment & 0 & 0 & 2 & 3 & 0 \\
\hline Economic/utilization & 6 & 0 & 2 & 14 & 3 \\
\hline \multicolumn{6}{|l|}{ Other clinical studies, $\mathbf{n}$} \\
\hline Clinical endpoint & 0 & 2 & 1 & 20 & 11 \\
\hline Patient-reported outcome & 5 & 1 & 1 & 17 & 4 \\
\hline Clinician global assessment & 0 & 0 & 3 & 0 & 0 \\
\hline Economic/utilization & 0 & 3 & 0 & 0 & 0 \\
\hline
\end{tabular}

FDA =U.S. Food and Drug Administration.

However, our study also indicates that, across the studies that payers reported reviewing, $11 \%$ of the information differed from information included in the FDA-required labeling. We found that $11 \%$ and $12 \%$ of the endpoints included in the reviewed RCTs and other clinical studies, respectively, differed from those reported in the drug's corresponding FDA-required labeling. While these endpoints most often assessed similar clinical outcomes as those featured in the FDA-required labeling, on occasion the endpoints addressed an outcome not included in the drug's labeling. For example, for 1 product, payers reported reviewing a study comparing 2 treatments, with fatigue-as measured on the Fatigue Impact Scale-as a secondary endpoint. ${ }^{9}$ The FDA-required labeling for this drug did not include fatigue as an endpoint in the clinical studies described.

Almost one third of the studies that payers reviewed were not RCTs (102 of 348). We found that the clinical studies other than RCTs that payers reported reviewing sometimes included endpoints that were different in some way from those featured in the FDA-required labeling. This observation is consistent with the fact that FDA regulations expressly recognize that the FDA-required labeling will "ordinarily" include only those studies "that support effectiveness for the labeled indications" and will not "include an encyclopedic listing of all, or even most, studies performed as part of the product's clinical development program." ${ }^{10}$ As an example of non-RCT information that payers cited in reviewing for coverage determinations, payers reported reviewing McErlane et al. (2013), a study reporting the findings from the British Society for Rheumatology Biologics Register, for rheumatoid arthritis that included an assessment of juvenile idiopathic arthritis using the European League Against Rheumatism disease response scale, a disease measurement scale that did not feature in either drug's FDA-required labeling. ${ }^{11}$

In determining whether a manufacturer's promotional claims are appropriate, the FDA generally assesses whether the claims are consistent with the product's FDA-required labeling (i.e., supported by "substantial evidence," which the FDA generally interprets as data from RCTs). Recently, the FDA has indicated, through final guidance, that certain claims that are "consistent with the FDA-required labeling" may be supported by "scientifically appropriate and statistically sound" evidence, rather than "substantial evidence."12 While this guidance may allow for expanded manufacturer communications, the FDA's regulatory framework may restrict other communications that payers deem important.

There is ongoing debate regarding the policy and legality of the FDA's regulatory framework and around appropriate evidentiary standards and regulations. ${ }^{13,14}$ Opponents of the existing regulations observe that while payers are unconstrained with respect to evidence that they can consider, manufacturers are restricted (with some exceptions) in their communications about clinical claims that meet the "substantial evidence" standard. These opponents argue that existing rules restrict communication of important information, such as evidence generated outside of traditional RCTs, for example, in real-world settings, and that the FDA's current approach raises First Amendment concerns. ${ }^{15}$ Proponents of the status quo counter that the regulations are necessary to support truthful and straightforward communications about drugs and that loosening rules could lead to promotion of treatments not supported by rigorous evaluation, which would increase the risk of adverse health outcomes. ${ }^{16}$

Our study found that on occasion payers cited evidence not included in FDA-required labeling, underscoring that payers deem important some information excluded from FDArequired labeling. This finding is consistent with expectations by the Centers for Medicare \& Medicaid Services (CMS) for Part D payers to consider CMS-approved compendia and the peer-reviewed medical literature (for oncology-related 


\section{TABLE 3 Patient-Reported Outcomes Featured in Studies Payers Reported Reviewing that Were} Not Included in Drug's FDA Label

\begin{tabular}{|c|c|c|c|c|c|c|}
\hline & $\begin{array}{c}\text { Rheumatoid } \\
\text { Arthritis }\end{array}$ & $\begin{array}{l}\text { Juvenile } \\
\text { Idiopathic } \\
\text { Arthritis }\end{array}$ & $\begin{array}{l}\text { Ankylosing } \\
\text { Spondylitis }\end{array}$ & $\begin{array}{l}\text { Multiple } \\
\text { Sclerosis }\end{array}$ & $\begin{array}{c}\text { Non-Small Cell } \\
\text { Lung Cancer }\end{array}$ & Total \\
\hline \multicolumn{7}{|l|}{ Randomized controlled trials, $\mathbf{n}$} \\
\hline Disease-specific HRQOL & 5 & 1 & 0 & 1 & 4 & 11 \\
\hline SF-36a & 13 & 0 & 7 & 0 & 0 & 20 \\
\hline Utility measure $^{b}$ & 2 & 0 & 3 & 0 & 2 & 7 \\
\hline Subject impression of global health & 0 & 0 & 0 & 7 & 1 & 8 \\
\hline Sleep & 1 & 0 & 1 & 0 & 0 & 2 \\
\hline Fatigue & 2 & 0 & 0 & 6 & 0 & 8 \\
\hline Depression & 0 & 0 & 0 & 0 & 0 & 0 \\
\hline Cognitive functioning & 0 & 0 & 0 & 0 & 0 & 0 \\
\hline Treatment satisfaction & 0 & 0 & 0 & 3 & 0 & 3 \\
\hline \multicolumn{7}{|l|}{ Other clinical studies, $\mathbf{n}$} \\
\hline Disease-specific HRQOL & 1 & 1 & 0 & 7 & 4 & 13 \\
\hline SF-36a & 2 & 0 & 0 & 1 & 0 & 3 \\
\hline Utility measure $^{\mathrm{b}}$ & 0 & 0 & 0 & 2 & 0 & 2 \\
\hline Subject impression of global health & 1 & 0 & 0 & 0 & 0 & 1 \\
\hline Sleep & 1 & 0 & 1 & 0 & 0 & 2 \\
\hline Fatigue & 0 & 0 & 0 & 4 & 0 & 4 \\
\hline Depression & 0 & 0 & 0 & 2 & 0 & 2 \\
\hline Cognitive functioning & 0 & 0 & 0 & 1 & 0 & 1 \\
\hline Treatment satisfaction & 0 & 0 & 0 & 0 & 0 & 0 \\
\hline \multicolumn{7}{|c|}{$\begin{array}{l}\text { aIncludes SF-36, SF-12, and their individual components. } \\
\text { bUtility measures include the EQ5D and HUI. } \\
\text { HRQOL=health-related quality of life; EQ5D=EuroQol Group } 5 \text { dimension standardized health-related quality of life instrument; HUI = Health Utilities Index; } \\
\text { SF-36=36-Item Short Form Survey; SF-12 = 12-Item Short Form Survey. }\end{array}$} \\
\hline
\end{tabular}

indications) when judging drug coverage. ${ }^{17}$ Moreover, as noted, manufacturers face uncertainty-and must make judgment calls-when communicating information not identical to that included in FDA-required labeling. For example, payer review of evidence that is similar to FDA-required labeling creates a conundrum for manufacturers, who may be concerned about whether such information may be proactively communicated. Our research suggests that drug companies, within limits, might be allowed to engage with payers on such evidence. ${ }^{18}$ In the setting of such limits, a lead could be taken from the 21st Century Cures Act-which allows manufacturer communication of certain health care economic information to payers and similar entities provided that the information is based on competent and reliable scientific evidence, is related to an approved indication, and includes certain disclosures-as well as recent FDA guidance setting forth the agency's interpretation of the relevant provisions in the 21 st Century Cures Act. While these provisions can provide useful considerations for policymakers, new policies could build on these provisions because, as demonstrated, payers already consider information that includes clinical evidence that goes beyond information included in FDA-required labeling. ${ }^{19}$

\section{Limitations}

Our study has a number of limitations. First, we considered only evidence that payers cited in their coverage policies, not the totality of relevant evidence available in the medical literature. It is unclear whether payers fully report the evidence that they reviewed when formulating their coverage decisions in their coverage policies.

Second, not all payers issued a coverage determination for each drug, and the volume of evidence that payers cited in their coverage policies varied considerably. Third, because the coverage policies included in the database of private payer decisions were current as of April 30, 2016, they may not be consistent with the payers' current coverage policies for these products.

Fourth, because some drugs in our sample have been on the market for longer than others, drugs differed in regards to the number of available RCTs and other clinical studies. For instance, while ramucirumab (approved in 2014 for the treatment of non-small cell lung cancer) was associated with 1 RCT and no other clinical studies, etanercept (approved in 1998 for the treatments of rheumatoid arthritis) was associated with 12 RCTs and 5 other clinical studies.

Finally, the date of drug approval may also affect the endpoints included in the reviewed clinical studies. It is likely that 
as the time from registration trials increases, so does the likelihood that different endpoints from those in the registration trial will be included in more recently performed clinical studies.

\section{Looking Forward}

Today, with more information available and rising health care costs, payers have a greater need to consider evidence when making coverage determinations. Although FDA-required labeling provides summary information regarding information that the FDA relied on in approving the product, it is not intended to provide exhaustive information about a product's approved uses.

Our study suggests that payers review at least some RCTs and other clinical studies that provide information beyond that included in the drug's FDA-required labeling. Yet, manufacturers often face uncertainty when proactively communicating information that is not necessarily identical to information included in the FDA-required labeling, hindering the dissemination of such information.

Future research should aim to advance the understanding of the evidence that payers use when making coverage and reimbursement decisions for drugs. A better understanding of payer evidence requirements would potentially expedite patient access to new products and aid manufacturers when designing clinical programs to support their products. In 2011, the FDA and CMS established the Program for Parallel Review of Medical Devices to provide a mechanism for the agencies to simultaneously review submitted clinical data for innovative medical devices, with the purpose of reducing the time between the device receiving FDA approval and receiving Medicare coverage. ${ }^{20}$ In 2016, the FDA and CMS announced that the Parallel Review program would be fully implemented and extended indefinitely. ${ }^{21}$ Private-sector initiatives that explore approaches similar to the Parallel Review program for drugs and commercial payers would be valuable.

\section{Conclusions}

We found that roughly two thirds of endpoints featured in the clinical studies cited by large U.S. commercial payers in their drug coverage policies were identical with the drugs' corresponding FDA-required labeling. An additional one quarter of endpoints cited pertained to information similar to that in FDA-required labeling. The remaining 12\% of endpoints cited by payers were not included in FDA-required labeling. Our findings highlight that payers consider relevant information beyond what is included in the FDA-required labeling when making coverage determinations. Recent FDA guidance is a welcome step in recognizing the needs of payers to have access to information consistent with FDA-required labeling that may not necessarily come directly from pivotal clinical trials. Our research suggests that the FDA, manufacturer, and payer communities should continue engaging with one another to appro- priately facilitate communication of information necessary to allow informed coverage decisions.

\section{Authors}

JAMES D. CHAMBERS, MPharm, MSc, PhD; ELLE F. POPE, BA, MPH; COLBY L. WILKINSON, BA; and PETER J. NEUMANN, ScD, The Center for the Evaluation of Value and Risk in Health, Tufts Medical Center, Boston, Massachusetts.

AUTHOR CORRESPONDENCE: James D. Chambers, MPharm, MSc, PhD, Associate Professor, Tufts Medical Center, 800 Washington St., \#63, Boston, MA 02111. Tel.: 617.636.8882;

E-mail: jchambers@tuftsmedicalcenter.org.

\section{DISCLOSURES}

This study was funded by an unrestricted grant from the Pharmaceutical Research and Manufacturers of America. The authors work with The Center for the Evaluation of Value and Risk in Health, which is partially supported through the CEA Registry Sponsorship program; the CEA Registry has received funding from the National Science Foundation, National Library of Medicine, Agency for Healthcare Research and Quality, Centers for Disease Control and Prevention, and a variety of pharmaceutical and device companies that subscribe to the data. Chambers reports personal fees from Health Advances, Ernst \& Young, Magellan Health, Summit Therapeutics, and Sanofi-Aventis, unrelated to this study. Neumann reports past advisory board work with Amgen, Avexis, Axovant, Bayer, Bluebird, Congressional Budget Office, Janssen, Merck, Novo Nordisk, Pacira, Paratek, and Sage; consulting work for Boston Health Economics, GSK, Precision Health Economics, Veritech, and Vertex; speaker fees from AbbVie, Celgene, and Roche; and grants from the Alzheimer's Association, Amgen, Gates, Lundbeck, NIH, NPC, and Sage, all unrelated to this study. The other authors have nothing to disclose.

\section{REFERENCES}

1. Federal Food, Drug, and Cosmetic Act. 21 USC ch. 9 \& 505(b)(1)(A). Available at: https://www.gpo.gov/fdsys/pkg/USCODE-2011-title21/pdf/ USCODE-2011-title21-chap9.pdf. Accessed October 12, 2018.

2. Federal Food, Drug, and Cosmetic Act. 21 USC ch. 9 \&502(a)(1). Available at: https://www.gpo.gov/fdsys/pkg/USCODE-2010-title21/html/ USCODE-2010-title21-chap9-subchapV-partA-sec352.htm. Accessed October 12, 20181.

3. Klasmeier C, Redish MH. Off-label prescription advertising, the FDA and the First Amendment: a study in the values of commercial speech protection. Am J Law Med. 2011;37(2-3):315-57.

4. Chambers JD, Chenoweth MD, Neumann PJ. Mapping U.S. commercial payers' coverage policies for medical interventions. Am J Manag Care. 2016;22(9):e323-28

5. Chambers JD, Wilkinson CL, Anderson JE, Chenoweth MD. Variation in private payer coverage of rheumatoid arthritis drugs. J Manag Care Spec Pharm. 2016;22(10):1176-81. Available at: https://www.jmcp.org/ doi/10.18553/jmcp.2016.22.10.1176.

6. Neumann PJ, Chambers JD. Medicare's enduring struggle to define "reasonable and necessary" care. N Engl J Med. 2012;367(19):1775-77.

7. AMCP Format Executive Committee. The AMCP Format for Formulary Submissions: welcome to version 4.0. J Manag Care Spec Pharm. 2016;22(5):444-46. Available at: https://www.jmcp.org/doi/full/10.18553/ jmcp.2016.16071. 
8. U.S. Food and Drug Administration. Drugs@FDA: FDA approved drug products. August 27, 2014. Available at: https://www.accessdata.fda.gov/ scripts/cder/daf/. Accessed September 26, 2018.

9. Vermersch P, Czlonkowska A, Grimaldi LM, et al. Teriflunomide versus subcutaneous interferon beta-la in patients with relapsing multiple sclerosis: a randomised, controlled phase 3 trial. Mult Scler. 2014;20(6):705-16

10. Specific requirements on content and format of labeling for human prescription drug and biological products described in § 201.56(b)(1). 21 CFR $\S 201.57(\mathrm{c})(15)$. April 1, 2006. Available at: https://www.gpo.gov/fdsys/pkg/ CFR-2006-title21-vol4/pdf/CFR-2006-title21-vol4-sec201-57.pdf. Accessed September 26, 2018

11. McErlane F, Foster HE, Davies R, et al. Biologic treatment response among adults with juvenile idiopathic arthritis: results from the British Society for Rheumatology Biologics Register. Rheumatology (Oxford). 2013;52(10):1905-13.

12. U.S. Food and Drug Administration. Medical product communications that are consistent with the FDA-required labeling-questions and answers. Guidance for industry. June 2018. Available at: https://www.fda. gov/downloads/drugs/guidancecomplianceregulatoryinformation/guidances/ ucm537130.pdf. Accessed September 26, 2018.

13. Thomas K. F.D.A. deal allows amarin to promote drug for off-label use. The New York Times. March 8, 2016. Available at: https://www.nytimes. com/2016/03/09/business/fda-deal-allows-amarin-to-promote-drug-for-offlabel-use.html?_r=0. Accessed September 26, 2018.

14. Richardson E. Health policy brief. Off-label drug promotion. Health Affairs. June 30, 2016. Available at: http://www.healthaffairs.org/healthpolicybriefs/brief.php?brief_id=159. Accessed September 24, 2018.
15. Spears JM. Health Affairs blog. Taking a data-driven, patient-centric approach to pharmaceutical company communication with health care professionals. Health Affairs. March 11, 2016. Available at: https://www.healthaffairs. org/do/10.1377/hblog20160311.053856/full/. Accessed September 26, 2018.

16. Avorn J. Health Affairs blog. The First Amendment and pharmaceutical promotion. Health Affairs. March 11, 2016. Available at: https://www. healthaffairs.org/do/10.1377/hblog20160311.053870/full/. Accessed September 26, 2018.

17. Centers for Medicare \& Medicaid Services. Chapter 6-Part D Drugs and Formulary Requirements. In: Medicare Prescription Drug Benefit Manual. January 15, 2016. Available at: https://www.cms.gov/Medicare/PrescriptionDrug-Coverage/PrescriptionDrugCovContra/Downloads/Part-D-BenefitsManual-Chapter-6.pdf. Accessed September 26, 2018.

18. Neumann PJ. Communicating and promoting comparative-effectiveness research findings. N Engl J Med. 2013;369(3):209-11.

19. 21 st Century Cures Act. Pub L No. 114-255, 130 Stat. 1033. December 13, 2016. Available at: https://www.gpo.gov/fdsys/pkg/PLAW114publ255/pdf/PLAW-114publ255.pdf. Accessed October 12, 2018.

20. U.S. Food and Drug Administration. Pilot program for parallel review of medical products. Fed Regist. 2011;76(196):62808. Available at: https://www. gpo.gov/fdsys/pkg/FR-2011-10-11/pdf/2011-25907.pdf. Accessed September 26, 2018.

21. U.S. Food and Drug Administration. Program for parallel review of medical devices. Fed Regist. 2016;81(205):73113-73115. Available at: https:// www.gpo.gov/fdsys/pkg/FR-2016-10-24/html/2016-25659.htm. Accessed September 26, 2018. 


\section{APPENDIX A Commercial Health Plans Included in Tufts Medical Center Specialty Drug Evidence and Coverage Database}

1. UnitedHealth Group

2. Anthem

3. Humana

4. Health Care Service Corporation

5. Aetna

6. Highmark

7. Centene Corporation

8. Independence Health Group

9. Guidewell (Florida's Blue Cross and Blue Shield)

10. Blue Cross Blue Shield Michigan

11. Blue Cross Blue Shield New Jersey

12. EmblemHealth

13. Carefirst

14. Blue Cross Blue Shield North Carolina

15. Cigna

16. Blue Cross Blue Shield Massachusetts

17. Blue Cross Blue Shield Tennessee

Source: National Association of Insurance Commissioners. Market share reports for the top 125 accident and health insurance groups and companies by state and countrywide. In: 2014 Accident and Health Policy Experience Report. Page 295.

2015. Available at: http://www.naic.org/documents/prod_serv_statistical_ahp_lr.pdf. Accessed October 12, 2018.

Note: Payers listed in order of size (premiums earned).

\begin{tabular}{l|l}
\hline \multicolumn{1}{c}{ APPENDIX B Drugs } & \multicolumn{1}{c}{ Included in Study } \\
\hline Diseases & \multicolumn{1}{c}{ Indicated Drugs } \\
\hline Ankylosing spondylitis & Secukinumab (Cosentyx) \\
& Adalimumab (Humira) \\
& Certolizumab pegol (Cimzia) \\
& Etanercept (Enbrel) \\
& Golimumab (Simponi) \\
& Infliximab (Remicade) \\
\hline Juvenile idiopathic arthritis & Abatacept (Orencia) \\
& Adalimumab (Humira) \\
& Etanercept (Enbrel) \\
& Tocilizumab (Actemra) \\
& Canakinumab (Ilaris) \\
\hline Multiple sclerosis & Dimethyl fumarate (Tecfidera) \\
& Dalfampridine (Ampyra) \\
& Fingolimod (Gilenya) \\
& Interferon beta-la (Avonex) \\
& Interferon beta-la (Rebif) \\
& Interferon beta-lb (Betaseron) \\
& Interferon beta-lb (Extavia) \\
& Peginterferon beta-la (Plegridy) \\
& Natalizumab (Tysabri) \\
& Teriflunomide (Aubagio) \\
& Alemtuzumab (Lemtrada) \\
& Glatiramer (Copaxone) \\
& Mitoxantrone (Novantrone) \\
\hline Rheumatoid arthritis & Nivolumab (Opdivo) \\
& Pembrolizumab (Keytruda) \\
& Ramucirumab (Cyramza) \\
& Paclitaxel (Abraxane) \\
& Bevacizumab (Avastin) \\
& Pemetrexed (Alimta) \\
& Crizotinib (Xalkori) \\
& Abatacept (Orencia) \\
& Adalimumab (Humira) \\
& Anakinra (Kineret) \\
& Certolizumab pegol (Cimzia) \\
& Etanercept (Enbrel) \\
& Golimumab (Simponi) \\
& Infliximab (Remicade) \\
& Rituximab (Rituxan) \\
& Tocilizumab (Actemra) \\
& Tofacitinib (Xeljanz) \\
&
\end{tabular}

